\title{
Aplikasi Identifikasi Huruf Braille Menggunakan Computer Vision Berbasis Raspberry Pi
}

\author{
Ramiati*, Siska Aulia dan Lifwarda \\ Program Studi Teknik Telekomunikasi, Jurusan Teknik Elektro, Politeknik Negeri Padang, \\ Padang, Sumatera Barat, Indonesia \\ *Corresponding author, e-mail: ramiati76@gmail.com
}

\begin{abstract}
Abstrak - Indera penglihatan merupakan sumber informasi pada manusia. Sebagian manusia diciptakan dengan keterbatasan indera penglihatan. Tunanetra melakukan aktifitas membaca serta menulis menggunakan huruf Braille, yaitu sistem cetakan berupa kode terdiri dari enam titik dalam berbagai kombinasi yang ditonjolkan pada kertas sehingga dapat diraba. Untuk memudahkan tunanetra dan masyarakat dalam menikmati karya-karya yang dihasilkan oleh penyandang tunanetra dibuat sistem pembacaan naskah berkarakterkan Braille dengan mempelajari karakter braille terlebih dahulu dari masing-masing karakternya. Penelitian ini membuat sistem identifikasi huruf braille menjadi suara menggunakan computer vision. Metodenya, pembacaan naskah berkarakter Braille dengan mempelajari karakter braille. Pertama, scanner atau kamera berbasis Raspberry Pi mengcapture karakter braille. Kedua, sistem mengkonversi karakter Braille ke bentuk abjad dengan pengolahan citra Optical Character Recognition. Pengenalan pola karakter Braille teks tulisan menggunakan Jaringan Saraf Tiruan. Hasil penelitian pengujian huruf braille berupa teks abjad a sampai z, dan sinyal suara pengucapan abjad menggunakan sistem Text To Speech. Sistem konversi braille menjadi suara bekerja dengan baik, dengan akurasi rata-rata pengujian sistem yaitu $88.462 \%$. Kondisi ini dicapai dengan menggunakan kertas HVS 70 gsm dan kertas gambar dengan database 52 citra latih. Sistem hanya dapat melakukan proses pengenalan pada satu karakter, sehingga dapat digunakan sebagai referensi penterjemah naskah karakter braille berbasis audio yang dapat didengarkan oleh tunanetra dan masyakat.
\end{abstract}

Kata Kunci : image processing, braille, OCR, JST, text to speech

\begin{abstract}
Sense of vision is a source of information on humans. Some humans are created with limited sense of sight. The blind performs reading and writing activities using Braille letters, a printed code system consisting of six dots in various combinations that are highlighted on the paper so that they can be touched. To facilitate the visually impaired and the public in enjoying the works produced by blind people, a script reading system is characterized by Braille by studying the braille characters in advance of each character. This research makes a braille letter identification system into sound using computer vision. The method, the reading of Braille character scripts by studying braille characters. First, a scanner or Raspberry Pi-based camera captures braille characters. Second, the system converts Braille characters into alphabetical shapes by processing Optical Character Recognition images. Recognition of Braille character patterns in written text using Artificial Neural Networks. The results of research on braille testing are in the form of alphabetical texts a through $z$, and the sound signal of the pronunciation of the alphabet uses the Text To Speech system. Braille to sound conversion system works well, with an average accuracy of system testing of $88.462 \%$. This condition is achieved by using 70 gsm HVS paper and drawing paper with a 52 training image database. The system can only carry out the process of recognition of one character, so it can be used as a reference translator of audio-based braille characters that can be heard by the visually impaired and the community.
\end{abstract}

Key words : image processing, braille, OCR, ANN, text to speech

\section{Pendahuluan}

Teknologi image processing dewasa ini terus dikembangkan supaya efektif dan efisien dalam kegiatan dan pekerjaan manusia. Image processing adalah suatu teknologi tentang penyelesaian pengolahan sinyal gambar atau citra, sehingga gambar tersebut lebih mudah untuk diproses. Penelitian pengolahan citra dan pengenalan pola citra huruf braille dikembangkan untuk memudahkan komunikasi dengan tunanetra. Sistem pengkonversi karakter Braille merupakan sistem yang dapat melakukan penerjemahan karakter Braille ke karakter latin secara otomatis. Sistem mengubah citra huruf braille dan identifikasi huruf abjad dan data biner dari Arduino UNO. Dari hasil pengujian huruf Braille dengan kamera 
menggunakan waktu dari 3 detik sampai dengan 5 detik maka tingkat akurasi $92,3 \%[1]$.

Penelitian yang dilakukan mengenai citra huruf braille yaitu konversi citra huruf braille menjadi teks tulisan latin. Sistem akan mengenali karakter Braille dan mengklasifikasikan karakter Braille menjadi tulisan teks menggunakan metode Optical Character Recognition. Kemudian sistem akan mengubah karakter braille yang telah menjadi karakter latin (teks) menjadi suara menggunakan sistem diphone (Teks To Speech) [2]. Penelitian lain Sistem Pengenalan Pola Huruf Braille Berbasis Audio Menggunakan Metode Naive Bayes [3]. Kemudian terinspirasi oleh keunggulan otak manusia, bidang Artificial Neural Network (ANN) atau jaringan sel-sel otak buatan telah dikembangkan untuk memungkinkan proses belajar diimplementasikan pada suatu sistem. ANN digunakan untuk mengidentifikasi karakter braille[4].

Panca indera merupakan sumber informasi pada manusia. Sebagian manusia diciptakan dengan keterbatasan indera penglihatan. Informasi merupakan hal yang sangat penting bagi semua orang termasuk penyandang tunanetra. Mereka yang mengalami gangguan penglihatan secara signifikan membutuhkan layanan pendidikan atau pembelajaran yang khusus. Penyampaian informasi dilakukan melalui berbagai media. Salah satu media yang sering digunakan yaitu media cetak seperti buku. Namun buku yang tersedia di pasaran tidak mengadaptasi cara penyandang tunanetra untuk menangkap informasi. Tunanetra melakukan aktifitas membaca serta menulis menggunakan karakter Braille. Penelitian ini menawarkan solusi alternatif untuk mengatasi permasalahan diatas yaitu alat bantu komunikasi baca tunanetra. Pada penelitian ini dirancang sistem aplikasi identifikasi huruf braille menggunakan computer vision. Sistem konversi huruf braille menggunakan metode Jaringan Saraf Tiruan (JST). Secara garis besar penelitian ini adalah pengolahan citra braille dengan output teks tulisan dan suara menggunakan scanner dan kamera berbasis Raspberry Pi, sehingga naskah berkarakter huruf braille dapat dinikmati dengan cara didengarkan.

\section{Metoda}

Pada penelitian ini dirancang sistem yang dapat mengkonversikan citra huruf Braille menjadi teks abjad dan suara (image to speech). Huruf braille adalah suatu kode berbentuk titik-titik timbul, dimana titik tersebut kombinasi enam titik yang ditonjolkan pada kertas[5]. Aplikasi sistem ini menggunakan teknologi computer vision secara manual dan berbasis wireless. Blok diagram penelitian ini dapat dilihat pada gambar 1 .

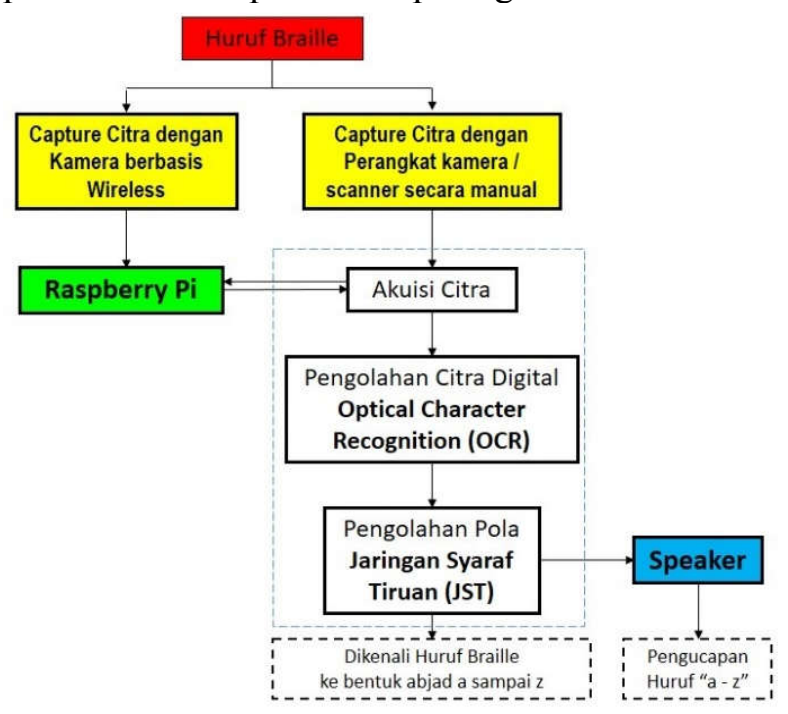

Gambar 1. Blok diagram Sistem Identifikasi Huruf Braille menjadi Suara Menggunakan Computer Vision

Pengambilan citra huruf braille pada sistem ini ada dua yaitu pengambilan citra dengan kamera atau scanner secara manual, dan pengambilan citra dengan kamera berbasis Raspberry Pi. Pengambilan citra berbasis wireless (Raspberry Pi) dilakukan tidak hanya untuk gambar diam tetapi gambar video, kemudian dilakukan pengolahan citra. Jenis pengolahan citra dalam bentuk video dan gambar melalui wireless adalah untuk melakukan proses pengamatan suatu objek yang tidak perlu dilakukan pengamatan secara langsung atau terus menerus pada suatu objek, namun cukup meletakkan suatu kamera yang mengarah pada objek yang diinginkan lalu mengamatinya dari layar monitor.

Citra braille yang telah diambil tersebut akan diolah dengan menggunakan metode Pengolahan Citra Digital Optical Character Recognition (OCR). Citra braille yang telah melewati proses pengolahan citra digital dengan metode OCR akan diteruskan pada proses pengenalan pola dengan menggunakan metode Jaringan Syaraf Tiruan (JST). Citra braille yang telah diolah dengan OCR di ekstraksi menggunakan ekstraksi ciri bentuk kemudian dilakukan proses pelatihan menggunakan JST, kemudian dilakukan proses pengujian terhadap data yang telah dilatih tadi apakah sesuai dengan model / database yang ada. 
Proses ini dapat dilihat pada gambar 3 perancangan perangkat lunak sistem identifikasi braille.

Citra braille yang telah dikenali dalam bentuk teks tersebut akan dikonversi lagi menjadi bentuk suara dengan menggunakan sistem Text to Speech yang ada pada Matlab R2017, dimana sistem tersebut akan megkonversi secara otomatis. Text to Speech (TTS) merupakan salah satu sistem dalam bidang teknologi bahasa, yang dapat mengkonversi teks dalam format suatu bahasa atau suatu karakter latin (karakter tertulis) menjadi ucapan sesuai dengan pembacaan teks dalam bahasa yang digunakan. Proses TTS dengan melakukan fonetisasi, yaitu penyusunan fonem-fonem untuk membentuk ucapan.

\subsection{Perancangan Perangkat Keras}

Pada perancangan aplikasi identifikasi huruf braille, sistem pengotrolan kamera berbasis wireless menggunakan perangkat jaringan Wireless IP (Internet Protocol) dan IPv4 DHCP (Dynamic Host Configuration Protocol. Desain perancangan perangkat keras penelitian pada gambar 2 .

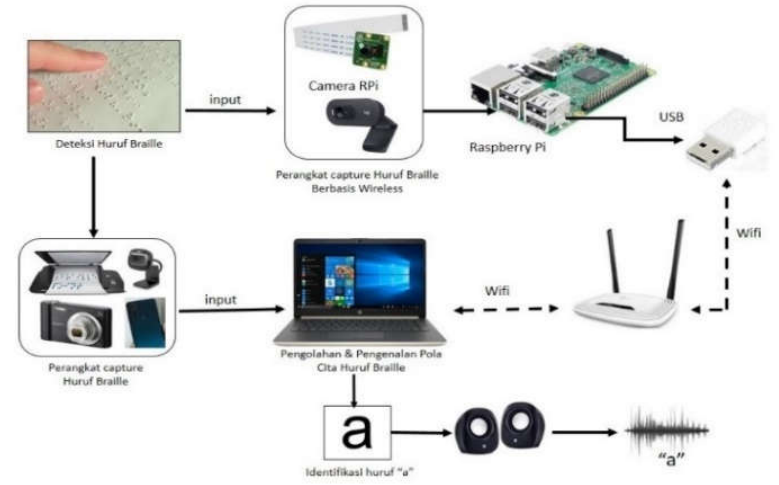

Gambar 2. Perancangan Aplikasi Identifikasi Huruf Braille Menjadi Sinyal Suara menggunakan Computer Vision

Berdasarkan gambar 2 perangkat keras berbasis wireless dalam sistem ini berupa 1 unit laptop sebagai user dan Raspberry Pi sebagai mini PC (server) dilengkapi kamera Raspberry Pi dan USB kamera (Logitech C270 HD), USB Wi-Fi dongle, dan wifi extender serta 1 unit router Sistem Operasi Mikrotik. Sedangkan untuk perangkat lunak RPi menggunakan system operasi MotionEyeOS dan aplikasi Motion untuk Surveillance Cam Huruf braille dicapture oleh kamera USB pada RPi, jadi fungsi IP ada pada RPi, sedangkan komunikasi pada camera melalui USB. Mini PC yang digunakan adalah Raspberry pi model B rev 1. Komunikasi antara RPi ke unit laptop menggunakan Wireless LAN (WLAN) melewati router.

Huruf braille yang akan diolah atau dikonversikan diambil dengan menggunakan scanner dan dapat juga menggunakan kamera atau webCam yang dapat dilakukan secara real time atau tidak. Scanner dan Kamera atau webCam yang dapat digunakan asalkan gambar atau citra yang ditangkap terlihat jelas dan objek yang ditangkap akan disesuaikan sesuai dengan kebutuhan yang diperlukan. Baik atau tidaknya hasil tangkapan image oleh scanner atau kamera tergantung dari spesifikasi internal dari scanner atau kamera itu sendiri. Perangkat capture huruf braille yang digunakan yaitu scanner Canon Canoscan Lide 20 dengan resolusi sebesar 600 dpi, kamera HP dengan resolusi kamera sebesar $12 \mathrm{MP}$, kamera digital Canon EOS M3 dengan resolusi 24 MP dan Kamera Logitech C270 HD WebCam serta Raspberry Pi Camera.

\subsection{Perancangan Perangkat Lunak}

Perancangan perangkat lunak pada penelitian ini terdiri dari akuisi citra huruf braille, pengolahan citra dengan Optical Character Recognition dan pengenalan pola citra huruf braille menggunakan Jaringan Saraf Tiruan. Blok diagram perancangan perangkat lunak pada gambar 3.

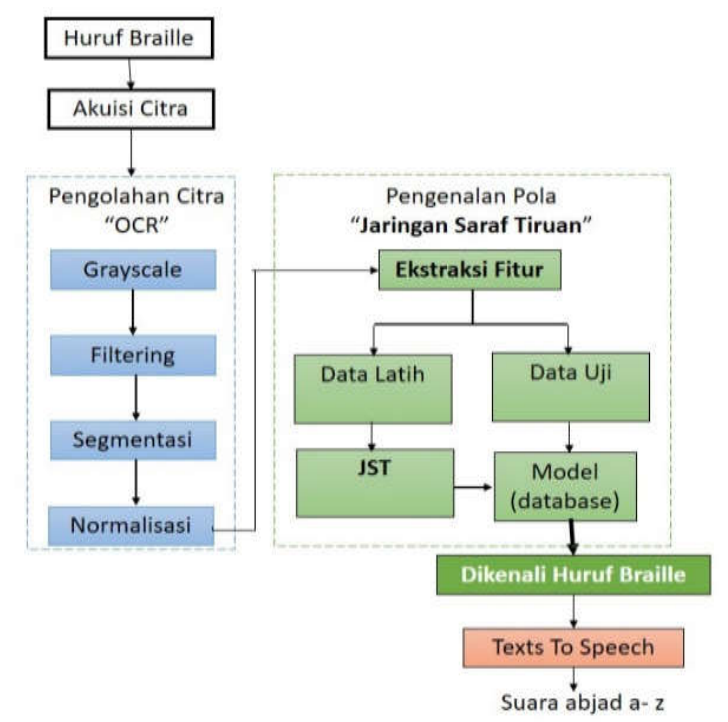

Gambar 3. Blok diagram Pengolahan dan Pengenalan Pola Citra Huruf Braille

Berdsarkan gambar 3, hasil akuisi citra dilakukan pengolahan citra digital menggunakan OCR untuk mengidentifikasi citra huruf braille yang dikonversi ke abjad a sampai z. Proses OCR pada penelitian ini meliputi grayscale, filtering, 
segmentasi dan normalisasi. Setelah itu, proses ektraksi fitur / ciri menggunakan metode segmen dan analisa warna citra. Ektraksi fitur menggunakan metode Multi-level thresholding berupa pola biner. Hasil ekstraksi fitur citra yaitu untuk memperoleh ciri-ciri tertentu dari karakter huruf yang diamati.

Ekstraksi fitur yang digunakan yaitu ekstraksi ciri pola biner. Ekstraksi ciri biner ini dilakukan dengan membagi gambar/citra huruf braille menjadi beberapa bagian yaitu baris $\mathrm{M}$ dan kolom N. Pola huruf braile terdiri dari 6 titik maka huruf braille dibagi menjadi 3 baris dan 2 kolom, matriks $3 \times 2$. Setiap baris dan kolom dilakukan identifikasi terhadap nilai 1 dan 0 , jika salah satu bagian berwarna putih maka bagian tersebut diberi nilai 1 dan jika bagian tersebut berwarna hitam maka bagian tersebut diberi nilai 0 .

Pengenalan pola JST dalam penelitian ini yaitu proses pelatihan (training) dan pengujian (testing). Proses pelatihan bertujuan untuk mendapatkan data latih dalam mengenali pola. Data latih merupakan algoritma klasifikasi untuk membentuk sebuah model klasifikasi karakter braille. Proses pengujian bertujuan untuk menguji data uji dalam mengenali pola setelah dilakukan proses pelatihan. Data uji merupakan suatu alat ukur sejauh mana klasifikasi model berhasil melakukan klasifikasi dengan benar, dan data uji ini juga digunakan untuk menghitung akurasi model klasifikasi yang dibentuk. Jika tingkat akurasi yang diperoleh sesuai dengan nilai yang ditentukan, maka model tersebut dapat digunakan untuk mengklasifikasikan data baru yang belum pernah dilatihkan atau diujikan sebelumnya.

Proses pengujian dan pelatihan menggunakan Jaringan Saraf Tiruan Radial Basis Function. Pada pelatihan JST radial basis function ini menggunakan nilai parameter tertentu, sesuai dengan data yang ada dapat dilihat pada tabel 1 .

Tabel 1. Training Parameters

\begin{tabular}{|c|c|c|}
\hline No. & Parameter & Value \\
\hline 1 & goal & $1 \mathrm{e}-6$ \\
\hline 2 & spread & 1 \\
\hline 3 & $\begin{array}{c}\text { MN (maximum number of } \\
\text { neurons) }\end{array}$ & 15 \\
\hline 4 & $\begin{array}{c}\text { DF (Number of neurons to } \\
\text { add between displays) }\end{array}$ & 25 \\
\hline
\end{tabular}

Proses pelatihan dilakukan dengan mengunakan nilai dari data latih, hasil latih dan nilai parameter yang digunakan, kemudian hasil pelatihan disimpan dalam bentuk net keluaran. Dan proses pengujian menggunakan folder yang berisikan data latih dan data uji yang akan dikenali terlebih dahulu dengan menggunakan ekstraksi ciri. Pembuatan dan Pengambilan Sampel Huruf Braille

Huruf Braille yang digunakan dalam penelitian ini dibuat secara manual (asli sesuai buku braille) dan secara buatan. Alat yang digunakan dalam pembuatan sampel huruf braille yaitu reglet (slate), alat tersebut sama halnya dalam penggunaan pena dalam pembuatan huruf biasa. Kertas yang digunakan dalam pembuatan sampel ini yaitu kertas HVS, Kertas Buku Gambar dan Kertas Jilid. Proses pembuatan huruf braille tersebut dapat dilihat pada gambar 4 .

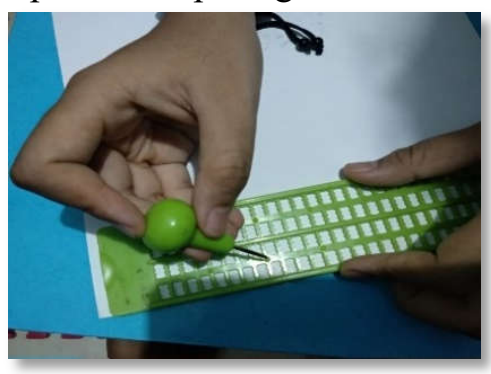

Gambar 4. Proses Pembuatan Sampel Huruf Braille dengan Reglet

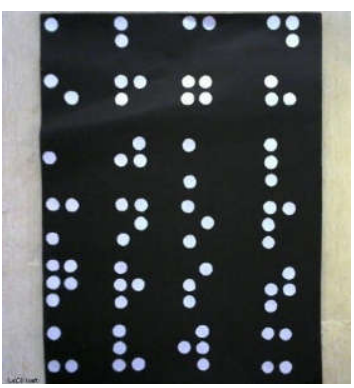

Gambar 5. Sampel Karakter Braille

Setelah sampel huruf braille selesai dibuat, Sampel tersebut akan dirubah menjadi sebuah citra. Proses pengambilan citra huruf braille yang akan digunakan dalam pembuatan aplikasi dilakukan dengan perangkat capture gambar secara manual dan berbasis wireless.

\section{3. Hasil dan Pembahasan}

\section{3 .1 Hasil Data Sampel Huruf Braille}

Setelah pengambilan citra dari sampel huruf braille a-z yang dapat dilihat pada gambar 6, kemudian dilakukan pemotongan citra tersebut menjadi perhuruf agar dapat dilakukan proses pengenalan masing-masing huruf braille tersebut dapat dilihat pada gambar 7 . 


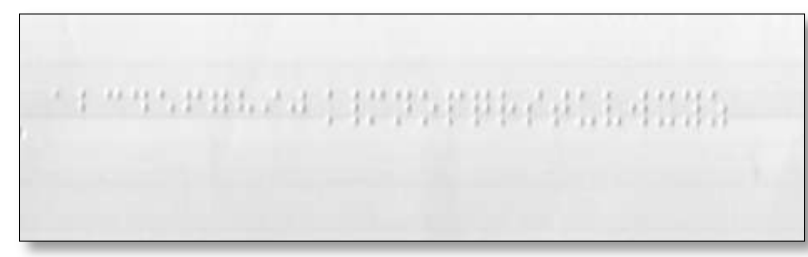

Gambar 6. Citra Huruf Braille a-z



Gambar 7. Citra Masing-Masing Huruf Braille

\section{Hasil Identifikasi Huruf Braille}

Hasil target latih untuk mengenali/ mengelompokkan masing-masing data latih. Target latih berupa angka dari 1 sampai 26 menggantikan abjad a sampai dengan z. Proses pelatihan dilakukan dengan mengunakan nilai dari data latih, hasil latih (gambar) dan nilai parameter yang digunakan, kemudian hasil pelatihan disimpan dalam bentuk net keluaran. Nilai akurasi yang didapatkan dari proses pelatihan JST RBF adalah $100 \%$ dapat dilihat pada gambar 9 .

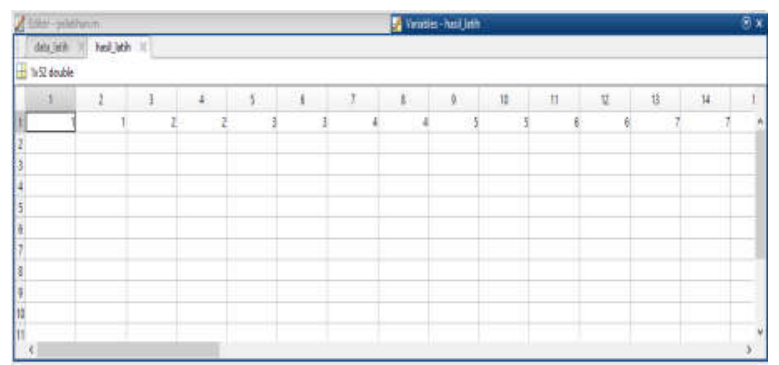

Gambar 8. Hasil Latih dari Data Latih



Gambar 9. Nilai Akurasi Pelatihan

\subsection{Pengambilan Data Huruf Braille dari server Raspberry Pi}

Pada pengambilan data kamera berbasis Raspberry Pi, dibutuhkan software Motion pada Sistem Operasi MotionEyeOs. Konfigurasi pada
Motion tersebut dalam capture gambar dilakukan secara manual dan time triggering sistem setiap 5 detik atau mengambil video, hasil tangkapan gambar kemudian data disimpan sementara di memory, lalu data di transfer ke PC Client yang telah dikonfigurasi melalui protokol File Transfer Protocol ( FTP ). Untuk melihat stream dari motion, masukan alamat 192.168.0.102:8081 pada browser disisi klien, maka akan tertampil stream seperti pada gambar 10 .

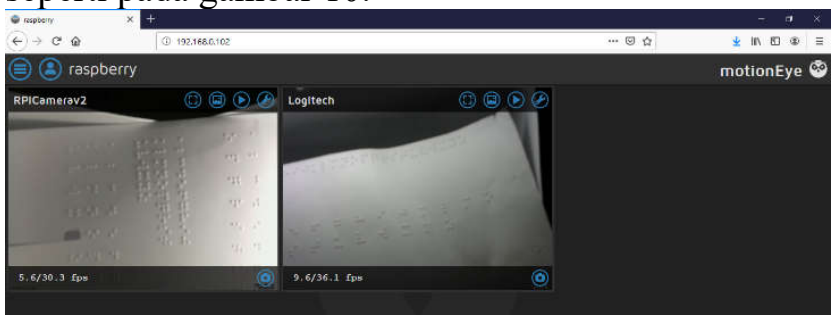

(a)

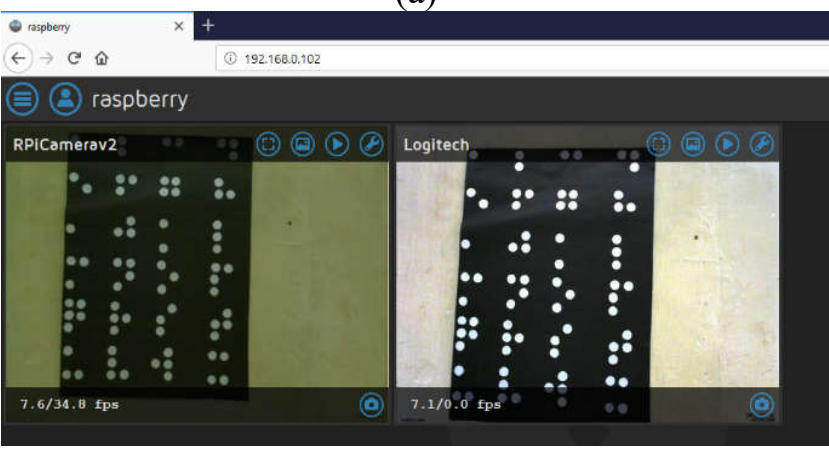

(b)

Gambar 10. Hasil Program Motion Identifikasi Huruf Braille (a)Huruf Braille dengan Reglet (b) Huruf Braile Buatan

Berdasarkan gambar 10, hasil sinyal video diproses di Raspberry Pi, kemudian gambar pada video tersebut dideteksi menggunakan program Motion. Motion mendeteksi hasil citra braille dengan memantau sinyal video dari RPi kamera dan webcam berbasis raspberry Pi. Untuk mengecek keberhasilan program motion pada sistem operasi motioneye OS yang hanya dapat bekerja pada browser web di PC Client, web browser menggunakan Google Chrome untuk melihat video streaming tertampil secara realtime tiga puluh fps (frame per second) untuk pengujian kemampuan framing pada RPi dan USB Kamera / webcam yang digunakan. Proses selanjutnya yaitu mengecek upload video hasil rekaman motion ketika terdeteksi gambar. Input citra untuk pengolahan sinyal citra Huruf braille diperoleh data dengan men-download citra dari Raspberry Pi. 


\subsection{Pengolahan Citra Huruf Braille}

Hasil pengolahan citra Huruf braille menggunakan metode OCR dapat dilihat pada gambar 11. Citra grayscale dari gambar 11 terdiri atas citra dengan warna abu-abu, bervariasi pada warna hitam merupakan bagian dengan intensitas terlemah dan warna putih merupakan bagian dengan intensitas terkuat. Hasil citra filtering untuk mengurangi noise pada citra, sehingga hasil citra yang diperoleh lebih halus. Segmentasi Citra menggunakan Thresholding. Tujuannya citra braille diekstrak untuk membedakan foreground (objek titik timbul) dari background (kertas) dan mengubah menjadi citra biner. Hasil citra normalisasi, dimana dimensi region tiap karakter citra dirubah ketebalan karakter citra tersebut.

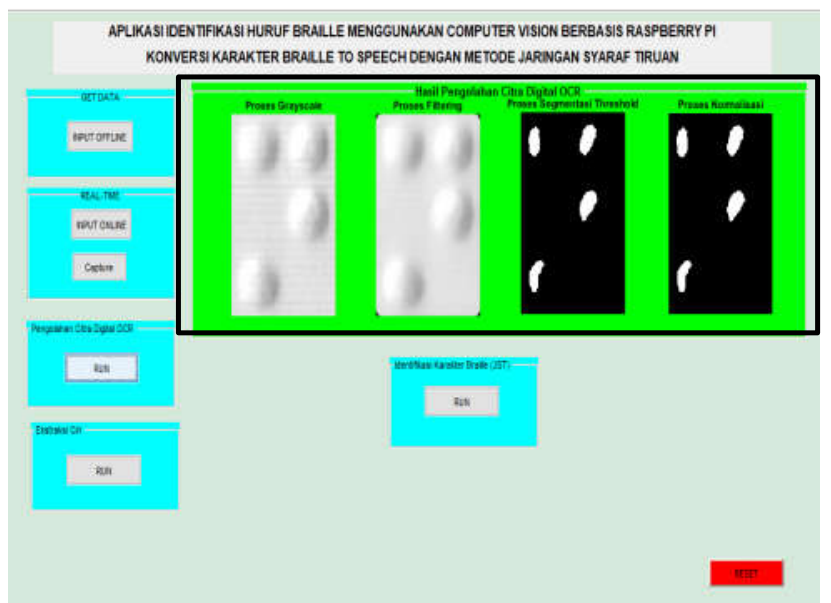

Gambar 11. Hasil Pengolahan Citra Huruf Braille dengan metode OCR

\subsection{Pengenalan Pola Huruf Braille dengan JST}

Hasil ekstraksi ciri huruf braille dengan ekstraksi ciri teknik pola biner pada gambar 12 .



Gambar 12. Hasil Pengenalan Pola Citra Huruf Braille dan Output Suara dengan JST
Pengenalan huruf Braille ke bentuk teks atau abjad, kemudian hasil teks dikonversi menjadi suara (pengucapan) dari citra huruf braille. Citra huruf braille tersebut harus melewati proses ekstraksi ciri biner agar dapat dikenali. Setelah dikenali kedalam bentuk teks/abjad, huruf tersebut akan ditampilkan kedalam bentuk suara dengan program text to speech. Hasil pengenalan huruf yang berhasil pada gambar 12 dan hasil yang gagal dapat dilihat pada gambar 13. Kemudian hasil dalam bentuk suara diimplementasikan secara langsung agar dapat didengar, dapat dilihat pada gambar 14.
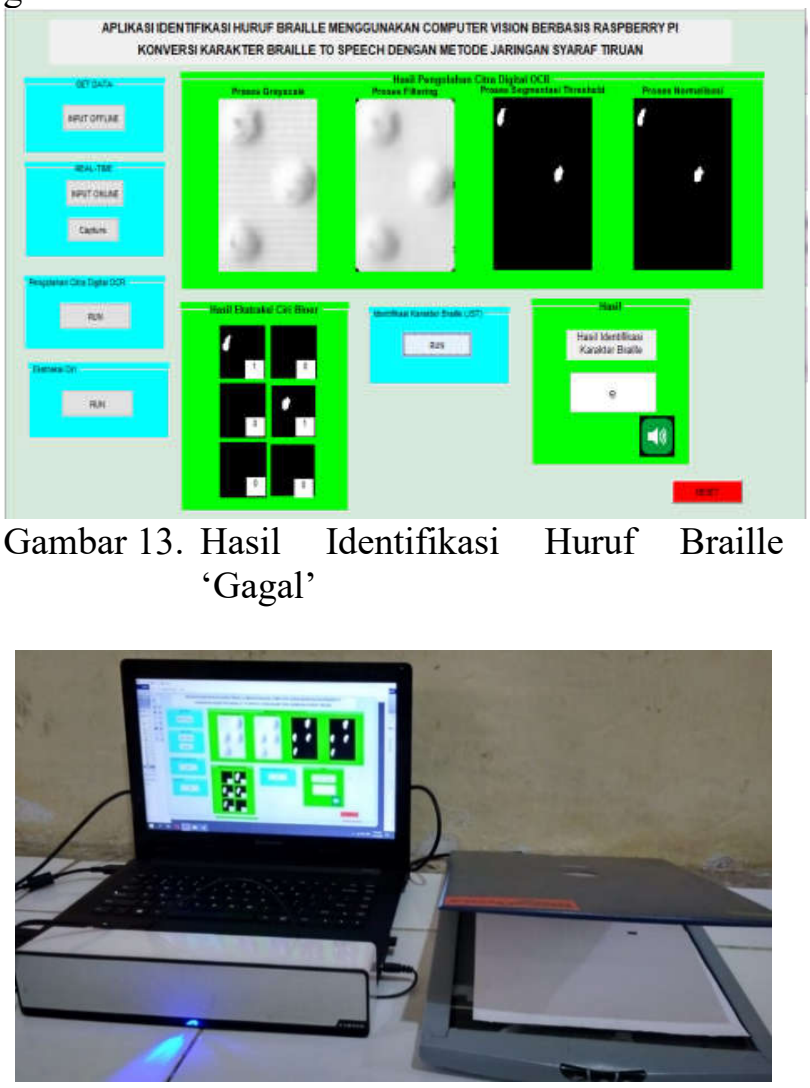

Gambar 14. Implementasi Identifikasi Huruf Braille Menjadi Sinyal Suara

\subsection{Hasil Pengujian Aplikasi Identifikasi Huruf Braille}

Pengujian dalam penelitian ini terdiri dari capture citra kamera secara manual dan kamera berbasis raspberry Pi. Pengujian pengenalan pola dengan JST terdiri dari data latih dan data uji dapat dilihat pada tabel 2. Data latih dan data uji yang digunakan yaitu sebanyak 52 sampel yang terdiri dari $2 \times 26$ huruf a-z. 
Tabel 2. Tingkat Akurasi Pengenalan Pola JST

\begin{tabular}{|l|c|c|}
\hline \multicolumn{1}{|c|}{ Data } & Keberhasilan & Ket. \\
\hline Data Latih & $100 \%$ & akurasi \\
\hline Data Uji & $100 \%$ & akurasi \\
\hline
\end{tabular}

Data uji untuk pengenalan pola huruf braille menggunakan berbagai macam kertas dengan tektur kertas berbeda dan semua kertas bewarna putih. Hasil pengujian huruf braille dengan data uji kertas gambar, kertas HVS dan kertas jilid dapat dilihat pada tabel 3. Pengenalan pola huruf braille berdasarkan ekstraksi tektur kertas.

Tabel 3. Hasil Eksperimen Pengujian Huruf Braille dengan Computer Vision

\begin{tabular}{|c|c|c|c|}
\hline Data & Benar & Salah & Akurasi(\%) \\
\hline Pengujian1 & 52 & 0 & 100 \\
\hline Pengujian2 & 47 & 5 & 90.3846 \\
\hline Pengujian3 & 50 & 2 & 96.1538 \\
\hline Pengujian4 & 35 & 17 & 67.3077 \\
\hline \multicolumn{2}{|r|}{ Rata-rata Pengujian } & 88.462 \\
\hline
\end{tabular}

Berdasarkan tabel 3 hasil pengujian secara manual dengan scanner menggunakan 52 sampel terhadap masing-masing pengujian. Pengujian pertama jenis kertas HVS 70 gsm dan kertas gambar, sampel dapat dikenali secara keseluruhan, tingkat akurasinya yaitu $100 \%$. Pengujian kedua sampel yang digunakan menggunakan jenis kertas gambar dan kertas jilid, dan ada beberapa sampel yang salah dikenali tingkat akurasinya 90,3846\%. Pengujian ketiga dengan menggunakan jenis kertas HVS 70 gsm dengan ukuran pixel yang berbeda dari 2 data uji sebelumnya, tingkat akurasinya yaitu $96,1538 \%$. Pengujian identifikasi huruf braille berikutnya dengan menggunakan kamera HP, kamera digital dan webcam. Hasil pengenalan karakter braille dengan menggunakan kamera $\mathrm{Hp}$ dapat dilihat pada gambar 15 .

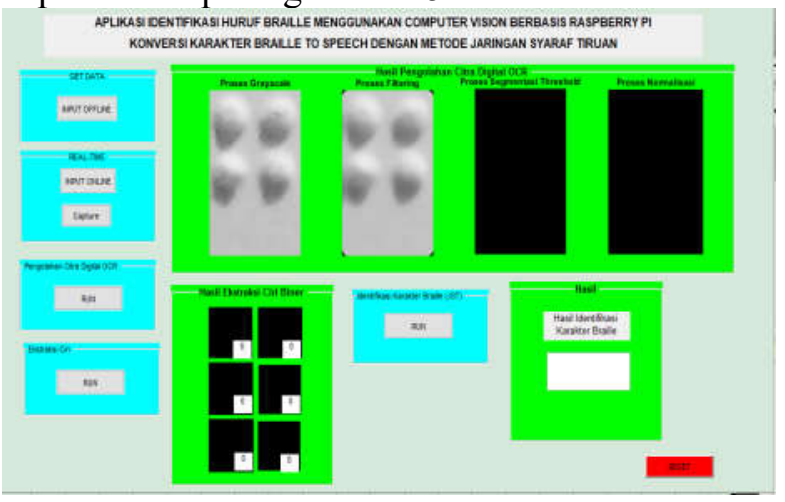

Gambar 15. Hasil Pengenalan Huruf Braille Menggunakan Kamera Hp 'Gagal'
Hasil pengenalan huruf braille dengan sampel citra yang ditangkap menggunakan kamera HP, kamera digital dan webcam tidak dapat dikenali oleh sistem dalam melakukan proses pengolahan citra digital dan proses seterusnya. Hasil akurasi yang dihasilkan sangat jauh dari kata sempurna, bisa dikatakan gagal karena hanya memiliki akurasi $3,8462 \%$ dan akurasi tersebut juga mengalami kesalahan (system error). Sampel tersebut tidak bisa dikenali ketahapan berikutnya walaupun telah menggunakan cahaya kilat dari kamera tersebut, dikarenakan pada proses penangkapan citra pada kamera telah melewati beberapa kompresi yang ada pada kamera sehingga ukuran kedalaman pada gambar semakin kecil. Selain itu juga dipengaruhi oleh intensitas cahaya dan penangkapan citra yang tidak tetap.

Pengujian keempat berdasarkan tabel 3 yaitu pengambilan data berbasis wireless atau server Raspberry Pi. Untuk hasil pengujian, tingkat akurasi kecil yaitu $67.3077 \%$. Sampel pengujian 26 sampel menggunakan kamera Raspberry Pi dan 26 sampel webcam Logitech C270 berbasis Raspberry Pi dengan sampel kertas gambar. Pengambilan data dilakukan secara berulang. Ketika pengambilan gambar huruf braille langsung hasilnya bisa dikatakan gagal, sehingga pengambilan menggunakan cahaya dengan ruang mini studio. Bentuk pengujian huruf braille berbasis Raspbery Pi pada gambar 16.



Gambar 16. Pengujian Huruf Braille Berbasis Raspberry Pi

Hasil empat pengujian identifikasi huruf braille menggunakan computer vision yang telah dilakukan, berdasarkan tabel 3 rata-rata akurasi pengujian identifikasi huruf braille yaitu $88.462 \%$. Hasil pengujian huruf braille berbasis Raspberry $\mathrm{Pi}$, dimana data sampel diperoleh dengan menggunakan sampel yang sebenarnya (sampel dari alat Reglet) tidak dapat dikenali, dikarenakan beberapa alasan yaitu objek atau sampel yang terlalu kecil, ketidakfokusan webcam atau kamera 
RPi dalam mengenali sampel, jarak webcam dengan sampel, dan intensitas cahaya yang digunakan. Sedangkan menggunakan sampel buatan pada gambar 5 dapat dikenali, karena ukuran sampel diperbesar beberapa kali lipat dari sampel yang sebenarnya sehingga jarak yang digunakan juga semakin jauh dapat dilihat pada gambar 17 dan gambar 18.

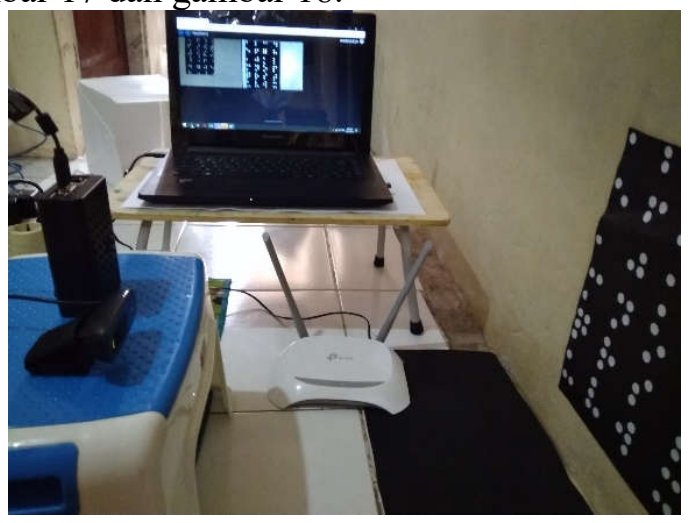

Gambar 17. Implementasi Pengujian Karakter Braille Berbasis Raspberry Pi



Gambar 18. Hasil Identifikasi Huruf Braille Output Suara Secara Real-Time dengan Kamera Raspberry Pi

\section{Kesimpulan}

Kesimpulan penelitian ini yaitu:

1. Pengambilan sampel citra huruf braille menggunakan media computer vision yaitu scanner, kamera HP, kamera digital, webcam dan kamera RPi. Hasil yang paling baik didapatkan dengan menggunakan scanner dengan jenis sampel kertas HVS 70 gsm dan kertas gambar karena jenis kertas dan ketebalan kertas mempengaruhi hasil pengenalannya.

2. Pembuatan sistem identifikasi huruf braille menjadi sinyal suara pada matlab berhasil dengan menggunakan metode OCR dan JST Radial Basis Function.
3. Pengkonversian huruf braille menjadi teks dan suara, proses pelatihan dan pengujian $100 \%$, pengujian 1 dengan akurasi $100 \%$, pengujian 2 akurasi $90.3846 \%$, pengujian 3 akurasi 96.15385 dan pengujian 4 dengan akurasi $67.3077 \%$.

\section{Ucapan Terima Kasih (Acknowledgement)}

Penelitian ini didanai dalam kegiatan penelitian dosen Politeknik Negeri Padang yaitu Penelitian Dana DIPA Politeknik Negeri Padang No. 179/PL9.1.4/PT.01.02/2019.

\section{Daftar Pustaka}

[1] Dewi Permata Sari, Sabilal Rasyad dan Evelina. 2017. Identifikasi Huruf Braille Berbasis Image Processing Secara Real Time. Seminar Nasional Sains dan Teknologi 2017. Fakultas Teknik Universitas Muhammadiyah Jakarta, 1-2 November 2017 p- ISSN : 2407 - 1846, eISSN : $2460-8416$.

[2] Luh Putu Eka Damayanthi, Made Windu Antara Kesiman dan I Made Agus Wirawan.2010. Pengembangan Aplikasi Text to Speech dalam Pembuatan Kamus untuk Tunanetra. Prosiding Seminar Nasional Pendidikan Teknik Informatika (SENAPATI) 2010 . Singaraja - Bali, 21 September 2010 . ISSN 2087-2658.

[3] Elsen Ronando dan Aris Sudaryanto. 2018. Sistem Pengenalan Pola Huruf Braille Berbasis Audio Menggunakan Metode Naïve Bayes . Jurnal Ilmu Komputer dan Desain Komunikasi Visual Vol 3, No 1, Juli 2018 ISSN (Cetak) : 2541-4550 ISSN (Online) : 2541-4585.

[4] K. Smelyakov, A. Chupryna, D. Yeremenko, A. Sakhon and V. Polezhai, "Braille Character Recognition Basd on Neural Networks," IEEE Second International Conference on Data Steam Mining \& Procssing August 21-25, 2018, Lviv, Ukraine.

[5] A. Windarto, I. I. Tritoasmoro, and S. A. Wibowo, "Desain Dan Simulasi Converter Braille Ke Suara Berbasis K- Nearest Neighbor ( KNN ) Dan Diphone Synthesis," Tek. Telekomun. Fak. Tek. Elektro, Univ. Telkom, 2012. 
[6] J. Hutauruk, R. Magdalena, and A. Rizal, "Perancangan Konverter Karakter Braille ke Suara Berbasis Pengolahan Citra Digital," Tek. Telekomun. Fak. Tek. Elektro, Univ. Telkom, 2013.

[7] Syahrullah, "Rancang Bangun Alat Bantu Baca Unanetra Berbasis Raspberry Pi," Jur. Tek. Inform. Fak. Sains dan Teknol. UIN Alauddin Makassar, 2018.

[8] I. S. Praditya Firmansyah, Wahyul Amien Syafei, "Pengenalan Teks Braille Berbasis Jaringan Syaraf Tiruan Feedforward Multilayer Dengan Menggunakan Metode Back Propagation," Mhs. Tek. Elektro Ekstensi 2003, Bid. Konsentrasi Elektron. dan Telekomun. Univ. Diponegoro Semarang, pp. 1-9, 2006.

[10] M. A. Nughroho, "Adaptive Genetic Algorithm (AGA) Radial Basis Function (RBF) Neural Network Untuk Klasifikasi," Jur. Inform. Fak. Mat. Ilmu Pengetah. Alam Univ. Sebel. Maret, 2012.

[11] M. Erwin and A. Haryono, "Pengenalan Huruf Menggunakan Model Jaringan Saraf Tiruan Radial Basis Function Dengan Randomize Cluster Decision," Lab. Pemrograman dan Inform. Teor. Tek. Inform. Fak. Teknol. Ind. Univ. Islam Indones., vol. 2005, no. Snati, 2005.

[12] Helmi Muhammad Shadiq, , Sudjadi, and Darjat. Perancangan Kamera Pemantau Nirkabel Menggunakan Raspberry Pi Model B.TRANSIENT, VOL.3, NO. 4, DESEMBER 2014, ISSN: 2302-9927, 547.

[13] M. Arakeri, Keerthana NS, Madhura M, A. sankar, and T. Munnavar, "Assistive Technologi for the Visually Impaired Using Computer Vision., 978-1-5386-5314, 2018 IEEE.

[14] V. Venkatesh Murthy and Haanumantappa, "Improving Optical Braille Recognition in Pre-processing Stage"., International Conference on Soft-computing and network Security (ICSNS), 2018 IEEE.

[15] M. W ajid, M. waris Abdullah and Dr. Omar Farooq., "Imprinted Braille-Character Pattern Recognition using Image Processing Techniues.," 2011 International Conference on Image Information Processing (ICIIP), IEEE.

[16] Yun Eninggar, Wahyul Amien Syafei, dan Budi Setyono. 2011. Pengenalan Huruf Braille Berbasis Jaringan Syaraf Tiruan
Metoda Hebbrule . Semarang : Fakultas Teknik Universitas, Diponegoro.

\section{Biodata Penulis}

Ramiati, menyelesaikan pendidikan S1 di ITP Padang. Diploma IV di PENS Surabaya dan S2 di UPI YPTK Padang. Saat ini bekerja sebagai dosen. di Jurusan Teknik Elektro Politeknik Negeri Padang.

Siska Aulia, menyelesaikan pendidikan S1 dan S2 di Universitas Andalas. Saat ini bekerja sebagai dosen di Jurusan Teknik Elektro, Politeknik Negeri Padang.

Lifwarda, menyelesaikan pendidikan S1 di ITS Surabaya dan S2 di UPI YPTK Padang. Saat ini bekerja sebagai dosen di Jurusan Teknik Elektro, Politeknik Negeri Padang. 